\title{
Determining the topology of peroxisomal proteins using protease protection assays
}

Tânia Francisco ${ }^{1,2}$, Ana F. Dias ${ }^{1,2,3}$, Ana G. Pedrosa ${ }^{1,2,3}$, Cláudia P. Grou ${ }^{1,2}$, Tony A.

Rodrigues $^{1,2,3}$, Jorge E. Azevedo ${ }^{1,2,3, *}$

${ }^{1}$ Instituto de Investigação e Inovação em Saúde, Universidade do Porto, Portugal

${ }^{2}$ Organelle Biogenesis and Function Group, Instituto de Biologia Molecular e Celular

(IBMC), Universidade do Porto, Rua Alfredo Allen, 208, 4200-135 Porto, Portugal

${ }^{3}$ Instituto de Ciências Biomédicas Abel Salazar (ICBAS), Universidade do Porto, Rua de

Jorge Viterbo Ferreira, 228, 4050-313 Porto, Portugal

*Corresponding author:

Jorge E. Azevedo

e-mail: jazevedo@ibmc.up.pt

Running Head: Protease protection assays 


\section{i. Abstract}

Protease protection assays are powerful tools to determine the topology of organelle proteins. Their simplicity, together with the fact that they are particularly suited to characterize endogenous proteins, are their major advantages and the reason why these assays have been in use for so many years. Here, we provide a detailed protocol to use with mammalian peroxisomes. Suggestions on how these assays can be controlled, and how to identify some technical pitfalls are also presented.

\section{ii. Keywords}

Peroxisome, peroxisomal proteins, protease protection assay, protein topology, proteinase K.

\section{Introduction}

Knowledge on the topology of peroxisomal proteins is crucial to understand their function. This is valid not only for enzymes, but also for all proteins involved in the biogenesis/structure of the organelle. Only then can one know whether a given enzyme acts on the cytosolic or organelle pools of its substrate or on which side of the peroxisomal membrane does a given protein-protein interaction take place.

Many different strategies can be used to define the topology of these proteins. For instance, in the case of mammalian peroxisomes immunofluorescence techniques using semipermeabilized cells have provided useful information [1-3]. However, whenever an antibody directed to a protein of interest is available, a simple protease protection assay 
using an organelle suspension can also provide valuable information [3-5]. The advantages of this approach are several-fold. First, it is very simple. Indeed, besides requiring just a few specific reagents (i.e., a protease and a protease inhibitor) and common protein analysis equipment (e.g., SDS-PAGE and Western-blotting apparatus), the whole procedure can be completed in a few hours. Second, any antibody that recognizes the protein of interest upon Western-blotting can be used in this approach. Finally, although organelle suspensions obtained from transfected cells expressing epitope-tagged versions of a protein can surely be used in these assays, the technique is particularly suited to characterize endogenous proteins. The latter situation is always preferred because all the potential problems associated with the use of transfected cells (i.e., protein missorting/incorrect topology due to abnormal expression levels or to the presence of tags) are avoided.

\section{Rationale and limitations of the method}

From a conceptual point of view, a protease protection assay could not be simpler.

Essentially, it relies on the fact that an exogenously added soluble protease will hydrolyze/degrade a given protein in an organelle suspension as long as the protein is accessible to the protease; if the protein (or a domain of it) is inside an intact organelle, then it will resist proteolysis (see Figure 1).

Despite its simplicity, several aspects need to be considered when performing a protease protection assay. A critical one regards the protease susceptibility of the protein of interest - the protein has to be susceptible to a selected protease under native conditions and in the absence of intact organelle membranes; otherwise no conclusions regarding its topology can be drawn from these experiments. Although this is generally not a problem - many 
peroxisomal proteins are at least partially susceptible to proteases - there are several exceptions. For instance, mammalian catalases and soluble urate oxidase from mouse liver peroxisomes are all extremely resistant to proteolysis, even when using aggressive proteases such as proteinase $\mathrm{K}(\mathrm{PK})$ or pronase $([6,7]$, unpublished results). Thus, it is always advisable to determine the protease susceptibility of the protein of interest before proceeding with a protease protection assay. A simple way to do this is described below (see subheading 3.1.1). In essence, an aggressive protease (e.g., $\mathrm{PK}$, pronase or trypsin) is added to Triton X-100-solubilized organelles, aliquots are removed at different time points and analyzed by SDS-PAGE/Western-blot. Ideally, the protein of interest should be completely digested (or converted into smaller fragment(s)) within the first minutes of digestion.

A protease protection assay always comprises three different types of samples. One sample simply contains intact/untreated organelles; another contains protease-treated intact organelles; and the third contains organelles that were disrupted before protease treatment. Two methods to disrupt organelles are provided in this protocol. One, the most commonly used, consists in adding a mild detergent (e.g., Triton X-100) to the organelle suspension to solubilize the peroxisomal membrane. The other consists in sonicating organelles in the presence of the exogenously added protease. In principle, the two methods will yield the same result, i.e., proteins (or protein domains) that resist proteolysis in the sample containing intact organelles will now be accessible to the protease and thus they may be cleaved. However, for membrane proteins or subunits of detergent-sensitive protein complexes the results may differ. For instance, PEX14, a 40-kDa peroxisomal intrinsic membrane protein [8], is cleaved into a $16-\mathrm{kDa}$ fragment by PK when intact or sonicated 
organelles are used in these assays, but is completely digested by the protease when the organelles are first solubilized with Triton X-100 [9]. Seemingly, membrane lipids or some PEX14-interacting protein protect the 16-kDa fragment of PEX14 from proteolysis by steric hindrance.

A protease protection assay is only conclusive when both the activity of the exogenously added protease and the intactness of organelle membranes are monitored. This is achieved by analyzing the behavior of organelle protein(s) of known topology. A first-choice mammalian peroxisomal protein to control these assays is PEX13, a 44-kDa transmembrane peroxin [3]. PEX13 is readily accessible to PK or trypsin in intact organelles yielding a protected fragment of $c a .28-30 \mathrm{kDa}$. However, upon disruption of the peroxisomal membrane, either by solubilization with mild detergents or by sonication, this fragment is completely degraded by these proteases [4]. Thus, by following the behavior of just one peroxisomal protein it is possible to monitor both the activity of the protease and the integrity of the peroxisomal membrane. If an anti-PEX13 antibody with the capacity to recognize the intraperoxisomal domain of PEX13 is not available, then there are other options. A good one consists in using an antibody directed to ABCD3 (also known as PMP70) and another directed to sterol carrier protein $\mathrm{x}(\mathrm{SCPx})$. ABCD3 is a 70-kDa transmembrane protein which is largely exposed at the cytosolic face of the peroxisomal membrane and is highly susceptible to most proteases [10]. Thus, it will be digested by the protease even when using intact organelles. SCPx is a 59-kDa peroxisomal matrix protein, which is partially processed upon import into the peroxisome, yielding two polypeptides of 46 and $13 \mathrm{kDa}$, respectively (reviewed in [11]). However, processing of SCPx is a very slow process in vivo and thus intact/unprocessed SCPx protein is detectable in most (if not 
all) organs/tissues [12]. Unprocessed SCPx will only be cleaved by the protease when the peroxisomal membrane is disrupted [6]. Note, however, that peroxisomes are quite fragile organelles and tend to release a fraction of their matrix proteins during tissue homogenization and even during simple manipulations such as sedimentation and resuspension [13]. Thus, a fraction of intact SCPx (and other matrix proteins) will actually be accessible to the protease when using intact organelles. The pool of intact SCPx that is relevant in these assays is thus the one that resists protease digestion in the sample containing intact organelles and is cleaved when the peroxisomal membrane is disrupted.

The protocol described here uses very large amounts of an aggressive protease to avoid misleading situations of partial proteolysis. Naturally, the protease should remain active during incubation with the organelle proteins but should be completely inactivated at the end of that incubation. Two strategies are used in tandem to inactivate the protease: 1) treatment with an irreversible protease inhibitor and 2) a fast denaturing protein precipitation step using trichloroacetic acid. Despite this, it is important to note that reactivation of the protease in subsequent steps (e.g., during SDS-PAGE) can still occur. Although this is a rare problem, it must always be considered; otherwise wrong conclusions will be drawn from these assays. This is actually quite easy to achieve - a comparison of protein patterns after Western-blotting should reveal several major bands, some of which run in the high molecular mass region of the gel, in all samples, including those containing protease-treated disrupted organelles. These bands correspond to proteins that are intrinsically resistant to proteolysis (e.g., catalase). Only Western-blots passing this simple quality control check should be probed with antibodies. 


\section{Materials}

\subsection{Protease protection experiments:}

1. Organelle suspension - Any organelle suspension prepared in an isotonic buffer (e.g., SEM buffer 1X; see below) can be used in this protocol. Excellent results are obtained with both purified peroxisomes and post-nuclear supernatants from rat/mouse liver (PNS; see Note 1) but other subcellular fractions (e.g., a peroxisome enriched "light mitochondria" fraction; [14]) can also be used. Rat/mouse liver is a first-choice organ to obtain these fractions for two reasons: 1) peroxisomes are very abundant in this organ (they comprise 2-3\% of total protein; [14]), and 2) hepatocytes can be disrupted using very gentle conditions thus yielding organelles of good quality ([14]). Other organs such as rat/mouse kidney, testis, adrenals, and spleen also yield excellent PNSs having a large fraction of intact organelles. Note, however, that with the exception of rat/mouse kidney $[15,16]$, it is still not possible to obtain highly pure peroxisomes from these organs. It is not necessary to use freshly prepared organelle suspensions for this protocol. PNS or purified peroxisome aliquots from rat/mouse liver that were snap frozen in liquid $\mathrm{N}_{2}$, stored at $-70{ }^{\circ} \mathrm{C}$ for several months, and rapidly thawed just before use also yield good results (see Note 2). Ultimately, the type of subcellular fraction selected for these assays depends on the sensitivity of the antibodies that will be used to detect the protein of interest and the peroxisomal proteins which will be used to control these assays (see Note 3).

2. SEM buffer 3X: 0.75 M sucrose, $60 \mathrm{mM}$ MOPS-KOH pH 7.2, 3 mM EDTA-NaOH pH 8.0 (keep at $4{ }^{\circ} \mathrm{C}$ ); 
3. $20 \mathrm{mM}$ MOPS-KOH pH 7.2 (keep at $4{ }^{\circ} \mathrm{C}$ );

4. $20 \mathrm{mg} / \mathrm{mL}$ Proteinase $\mathrm{K}$ in $20 \mathrm{mM}$ MOPS- $\mathrm{KOH} \mathrm{pH} 7.2$ (store as single-use aliquots at $\left.-70{ }^{\circ} \mathrm{C}\right)$;

5. $50 \mathrm{mg} / \mathrm{mL}$ phenylmethylsulfonyl fluoride (PMSF) in $100 \%$ ethanol (store at $-20^{\circ} \mathrm{C}$; Hazardous! Handle with care.);

6. $20 \%(\mathrm{w} / \mathrm{v})$ Triton X-100 (TX-100);

7. Ultrasonic homogenizer (e.g., SONOPULS HD2200-BANDELIN equipped with an MS 73 microtip);

8. $100 \%(w / v)$ trichloroacetic acid (TCA) (TCA is very corrosive. Hazardous! Handle with care.);

9. Acetone;

10. Microcentrifuge.

\subsection{SDS-PAGE and Western-blotting:}

1. Standard equipment and solutions required to perform SDS-PAGE/Westernblotting;

2. Laemmli sample buffer $1 \mathrm{X}$ : $50 \mathrm{mM}$ Tris $\mathrm{pH} 8.8,2 \mathrm{mM}$ EDTA-NaOH pH 8.0, 2\% (w/v) SDS, $0.02 \%(w / v)$ bromophenol blue;

3. $0.45 \mu \mathrm{m}$ nitrocellulose membrane (e.g., Amersham, 10600002);

4. Ponceau S stain: $0.2 \%(w / v)$ Ponceau $\mathrm{S}$ in $3 \%(\mathrm{w} / \mathrm{v}) \mathrm{TCA}$;

5. Antibodies - Besides one antibody directed to the protein being characterized, it is necessary to apply antibodies directed to peroxisomal proteins of known topology. As stated above an anti-PEX13 antibody $[4,17]$ that recognizes the intraperoxisomal domain of this protein in Western-blots is sufficient to control 
both the protease activity and the intactness of the peroxisomal membrane.

Alternatively, use antibodies directed to SCPx (e.g., ProteinTech $\left.{ }^{\mathrm{TM}}, 19182-1-\mathrm{AP}\right)$

and ABCD3 (e.g., Sigma-Aldrich ${ }^{\circledR}$, SAB4200181).

\section{Methods}

\subsection{Protease protection experiments:}

\subsubsection{Preliminary experiment: Intrinsic protease susceptibility of the protein of} interest

1. Assemble the reaction on ice according to Table 1. Mix well by inverting the tube a few times.

2. Remove a $196 \mu \mathrm{L}$ aliquot (0’) and keep on ice.

3. Add $16 \mu \mathrm{L}$ of $20 \mathrm{mg} / \mathrm{mL}$ PK ( $400 \mu \mathrm{g} / \mathrm{mL}$ final concentration) to tube 1 (see Notes 2 and 4) and incubate on ice. Remove aliquots of $200 \mu \mathrm{L}$ at different time points (e.g., 5', $10^{\prime}, 20^{\prime}$ and $\left.40^{\prime}\right)$ and, immediately, add $2 \mu \mathrm{L}$ of $50 \mathrm{mg} / \mathrm{mL}$ PMSF to each aliquot to inhibit PK (see Note 5). Mix gently, spin down for $1 \mathrm{sec}$ to collect the content at the bottom of the tube and incubate for $2 \mathrm{~min}$ on ice.

4. As soon as the previous 2-min incubation is finished precipitate proteins in samples with $10 \%$ TCA (final concentration). For this, add $22 \mu \mathrm{L}$ of $100 \%$ TCA to each aliquot, vortex and incubate for at least $30 \mathrm{~min}$ on ice.

5. Centrifuge at $11,300 \times g$ for $15 \mathrm{~min}$ at $4{ }^{\circ} \mathrm{C}$ and discard the supernatant.

6. Add $1 \mathrm{~mL}$ of acetone to the pellets. Vortex vigorously and centrifuge at $11,300 \times \mathrm{g}$ for 15 min at $4{ }^{\circ} \mathrm{C}$. 
7. Discard the supernatant. Spin down for $1 \mathrm{sec}$ and remove all traces of the acetone supernatant. Dry the pellets at $37^{\circ} \mathrm{C}(2-5 \mathrm{~min})($ see Note 6).

8. Resuspend protein pellets in Laemmli sample buffer $1 \mathrm{X}$, incubate at $65^{\circ} \mathrm{C}$ for $10 \mathrm{~min}$ and then at $90{ }^{\circ} \mathrm{C}$ for $5 \mathrm{~min}$, with shaking. Proceed to "SDS-PAGE and WesternBlotting" (see Subheading 3.2).

\subsubsection{Protease protection assay:}

1. Prepare samples according to Table 2 (Mix the first two components well before adding the organelle suspension).

2. Immediately after adding PK, sonicate tube 4 for $20-30 \mathrm{sec}$ ( $10 \%$ output power, $40 \%$ duty cycle) (see Note 7).

3. Incubate all tubes for $40 \mathrm{~min}$ on ice.

4. Add $2 \mu \mathrm{L}$ of $50 \mathrm{mg} / \mathrm{mL}$ PMSF to each tube. Mix gently, spin down samples for $1 \mathrm{sec}$, and incubate for 2 min on ice (see Note 5).

5. Proceed as in steps 4-8 of the preliminary experiment (see Subheading 3.1.1).

\subsection{SDS-PAGE and Western-Blotting}

1. Subject samples to SDS-PAGE/Western-blot.

2. Stain the nitrocellulose membrane with a reversible stain (e.g., Ponceau $\mathrm{S}$ ) and keep a digital record (see Note 8).

3. Probe the membrane with relevant antibodies (see Note 9). 


\section{Notes}

1. When preparing a PNS, the total cell homogenate should be centrifuged twice ( 600 $\mathrm{x} g$ for $10 \mathrm{~min}$ at $4{ }^{\circ} \mathrm{C}$ ) to ensure that intact cells and large plasma-membrane vesicles containing cytoplasm are completely removed.

2. Both the organelle suspensions and the protease stock solution (e.g., PK) should be quickly thawed in your hands, gently flicking the tubes to homogenize the suspensions/solutions, placed on ice and promptly used.

3. The amount of protein to be used depends on the nature of the organelle suspension and has to be adjusted accordingly. When using purified peroxisomes, 10-30 $\mu \mathrm{g}$ of protein per reaction are sufficient, whereas for PNS, $80-150 \mu \mathrm{g}$ of total protein may be necessary.

4. PK is used throughout this protocol, but other proteases, such as pronase or trypsin at a final concentration of $400 \mu \mathrm{g} / \mathrm{mL}$ should also be tested.

5. PMSF in the stock solution precipitates on ice; keep at room temperature and ensure all PMSF is in solution before using it.

6. Make sure that all acetone evaporates.

7. Sample heating must be avoided. Sonication is performed on ice and for short periods of time (e.g., cycles of $5 \mathrm{sec})$. Also, be careful to avoid protein foaming during sonication.

8. The nitrocellulose membrane should be stained with Ponceau $\mathrm{S}$ to assess protein loadings and a digital record of it should be kept. Please note that the overall protein pattern does not change extensively after proteolysis. This is true even for samples 
containing protease-treated disrupted organelles. Indeed, only minor alterations are observed since many abundant proteins are intrinsically resistant to proteolysis (e.g., catalase and urate oxidase; please see Refs. [6] and [7], respectively).

9. As it will be necessary to probe the membrane with several antibodies and since some proteins may co-migrate or present a complex proteolysis pattern, it is generally necessary to run several sample sets of the same assay. Just scale-up the reactions accordingly.

\section{References}

1. Fransen M, Brees C, Baumgart E, Vanhooren JCT, Baes M, Mannaerts GP, Van Veldhoven PP (1995) Identification and characterization of the putative human peroxisomal c-terminal targeting signal import receptor. J Biol Chem 270:77317736.

2. Schrader M (1998) Expression of PEX11beta Mediates Peroxisome Proliferation in the Absence of Extracellular Stimuli. J Biol Chem 273:29607-29614. doi: $10.1074 / j b c .273 .45 .29607$

3. Gould SJ, Kalish JE, Morrell JC, Bjorkman J, Urquhart AJ, Crane DI (1996) Pex13p is an $\mathrm{SH} 3$ protein of the peroxisome membrane and a docking factor for the predominantly cytoplasmic PTs1 receptor. J Cell Biol 135:85-95. doi: $10.1083 / j \mathrm{jcb} .135 .1 .85$

4. Gouveia AM, Reguenga C, Oliveira ME, Sa-Miranda C, Azevedo JE (2000) Characterization of peroxisomal Pex 5p from rat liver. Pex5p in the Pex 5p-Pex 14p membrane complex is a transmembrane protein. J Biol Chem 275:32444-51. doi: 10.1074/jbc.M004366200 
5. Honsho M, Asaoku S, Fukumoto K, Fujiki Y (2013) Topogenesis and homeostasis of fatty acyl-CoA reductase 1. J Biol Chem 288:34588-98. doi:

10.1074/jbc.M113.498345

6. Francisco T, Rodrigues TA, Freitas MO, Grou CP, Carvalho AF, Sá-Miranda C, Pinto MP, Azevedo JE (2013) A cargo-centered perspective on the PEX5-mediated peroxisomal protein import pathway. J Biol Chem 288:29151-29159. doi:

10.1074/jbc.M113.487140

7. Freitas MO, Francisco T, Rodrigues TA, Lismont C, Domingues P, Pinto MP, Grou CP, Fransen M, Azevedo JE (2015) The peroxisomal protein import machinery displays a preference for monomeric substrates. Open Biol 5:140236. doi:

10.1098/rsob.140236

8. Will GK, Soukupova M, Hong X, Erdmann KS, Kiel J a, Dodt G, Kunau WH, Erdmann R (1999) Identification and characterization of the human orthologue of yeast Pex14p. Mol Cell Biol 19:2265-77.

9. Oliveira MEM, Reguenga C, Gouveia AMM, Guimarães CP, Schliebs W, Kunau WH, Silva MT, Sá-Miranda C, Azevedo JE (2002) Mammalian Pex14p: membrane topology and characterisation of the Pex14p-Pex14p interaction. Biochim Biophys Acta 1567:13-22.

10. Kamijo K, Taketani S, Yokota S, Osumi T, Hashimoto T (1990) The 70-kDa peroxisomal membrane protein is a member of the $\mathrm{Mdr}$ (P-glycoprotein)-related ATP-binding protein superfamily. J Biol Chem 265:4534-40.

11. Gallegos AM, Atshaves BP, Storey SM, Starodub O, Petrescu AD, Huang H, Mcintosh AL, Martin GG, Chao H, Kier AB, Schroeder F (2001) Gene structure, intracellular localization, and functional roles of sterol carrier protein-2. Prog Lipid 
Res 40:498-563.

12. Ossendorp BC, Voorhout WF, van Amerongen A, Brunink F, Batenburg JJ, Wirtz KW (1996) Tissue-specific distribution of a peroxisomal 46-kDa protein related to the 58-kDa protein (sterol carrier protein $\mathrm{x}$; sterol carrier protein 2/3-oxoacyl-CoA thiolase). Arch Biochem Biophys 334:251-60. doi: 10.1006/abbi.1996.0453

13. Alexson SEH, Fujiki Y, Shio H, Lazarow PB (1985) Partial Disassembly of Peroxisomes. J Cell Biol 101:294-305.

14. Leighton F, Poole B, Beaufay H, Baudhuin P, Coffey JW, Fowler S, De Duve C (1968) The large-scale separation of peroxisomes, mitochondria, and lysosomes from the livers of rats injected with triton WR-1339. Improved isolation procedures, automated analysis, biochemical and morphological properties of fractions. J Cell Biol 37:482-513.

15. Zaar K, Völkl A, Fahimi HD (1989) D-aspartate oxidase in rat, bovine and sheep kidney cortex is localized in peroxisomes. Biochem J 261:233-8.

16. Wiese S, Gronemeyer T, Ofman R, Kunze M, Grou CP, Almeida JA, Eisenacher M, Stephan C, Hayen H, Schollenberger L, Korosec T, Waterham HR, Schliebs W, Erdmann R, Berger J, Meyer HE, Just W, Azevedo JE, Wanders RJA, Warscheid B (2007) Proteomics characterization of mouse kidney peroxisomes by tandem mass spectrometry and protein correlation profiling. Mol Cell Proteomics 6:2045-57. doi: 10.1074/mcp.M700169-MCP200

17. Fransen M, Wylin T, Brees C, Mannaerts GP, Veldhoven PP Van (2001) Human Pex19p Binds Peroxisomal Integral Membrane Proteins at Regions Distinct from Their Sorting Sequences. Mol Cell Biol 21:4413-4424. doi:

10.1128/MCB.21.13.4413 


\section{Figure caption:}

Fig. 1- Graphic representation of the different experimental conditions used to assess the topology of peroxisomal proteins.

\section{Acknowledgements}

This work was financed by FEDER - Fundo Europeu de Desenvolvimento Regional, funds through the COMPETE 2020 - Operacional Programme for Competitiveness and Internationalization (POCI), Portugal 2020, and by Portuguese funds through FCT Fundação para a Ciência e a Tecnologia/ Ministério da Ciência, Tecnologia e Inovação in the framework of the projects "Institute for Research and Innovation in Health Sciences" (POCI-01-0145-FEDER-007274) and "The molecular mechanisms of peroxisome biogenesis" (PTDC /BEX-BC M/2311/2014), and through Norte 2020 - Programa Operacional Regional do Norte, under the application of the "Porto Neurosciences and Neurologic Disease Research Initiative at i3S (NORTE-01-0145-FEDER-000008)”. T.F, A.F.D., C.P.G. and T.A.R. were supported by Fundação para a Ciência e a Tecnologia, Programa Operacional Potencial Humano do QREN and Fundo Social Europeu.

Table 1. Sample preparation:

\begin{tabular}{|l|c|c|}
\hline Components & Per time point & Tube 1 \\
\hline ddH ${ }_{2} \mathbf{O}$ & To $200 \mu \mathrm{L}$ & $(603-5 \mathrm{x}) \mu \mathrm{L}$ \\
\hline SEM buffer 3X & $1 \mathrm{X}$ & $327 \mu \mathrm{L}$ \\
\hline Organelle suspension & $\begin{array}{c}10 \mu \mathrm{g}-150 \mu \mathrm{g} \\
(\text { see Notes } \mathbf{2} \text { and } \mathbf{3})\end{array}$ & $5 \mathrm{x} \mu \mathrm{L}$ \\
\hline $\mathbf{2 0 \%}(\mathbf{w} / \mathbf{v})$ TX-100 & $1 \%$ & $50 \mu \mathrm{L}$ \\
\hline
\end{tabular}




\begin{tabular}{|c|c|c|c|c|c|}
\hline \multirow{2}{*}{\multicolumn{2}{|c|}{ Table 2. Reactions assembly: }} & \multirow{3}{*}{\begin{tabular}{c|} 
Tube 1 \\
- PK
\end{tabular}} & \multirow{3}{*}{$\begin{array}{c}\text { Tube } 2 \\
+ \text { PK }\end{array}$} & \multirow{3}{*}{$\begin{array}{c}\text { Tube } 3 \\
+\mathrm{PK} /+\mathrm{TX}-100\end{array}$} & \multirow{3}{*}{$\begin{array}{c}\text { Tube } 4 \\
+\mathrm{PK} /+ \text { sonication }\end{array}$} \\
\hline & & & & & \\
\hline Components & Per reaction & & & & \\
\hline $\mathrm{ddH}_{2} \mathrm{O}$ & To $200 \mu \mathrm{L}$ & $(129.3-\mathrm{x}) \mu \mathrm{L}$ & $(129.3-\mathrm{x}) \mu \mathrm{L}$ & $(119.3-\mathrm{x}) \mu \mathrm{L}$ & $(129.3-\mathrm{x}) \mu \mathrm{L}$ \\
\hline SEM buffer 3X & $1 X$ & $66.7 \mu \mathrm{L}$ & $66.7 \mu \mathrm{L}$ & $66.7 \mu \mathrm{L}$ & $66.7 \mu \mathrm{L}$ \\
\hline Organelle suspension & $\begin{array}{c}10 \mu \mathrm{g}-150 \mu \mathrm{g} \\
\text { (see Notes } 2 \text { and } 3 \text { ) }\end{array}$ & $\mathrm{x} \mu \mathrm{L}$ & $\mathrm{x} \mu \mathrm{L}$ & $\mathrm{x} \mu \mathrm{L}$ & $\mathrm{x} \mu \mathrm{L}$ \\
\hline $20 \%(w / v) T X-100$ & $1 \%$ & - & - & $10 \mu \mathrm{L}$ & - \\
\hline 20 mM MOPS pH 7.2 & $4 \mu \mathrm{L}$ & $4 \mu \mathrm{L}$ & - & - & - \\
\hline $20 \mathrm{mg} / \mathrm{mL}$ PK & $\begin{array}{c}400 \mu \mathrm{g} / \mathrm{mL} \\
(\text { see Notes } 2 \text { and 4) } \\
\end{array}$ & - & $4 \mu \mathrm{L}$ & $4 \mu \mathrm{L}$ & $4 \mu \mathrm{L}$ \\
\hline
\end{tabular}




\section{Protease protection assay}

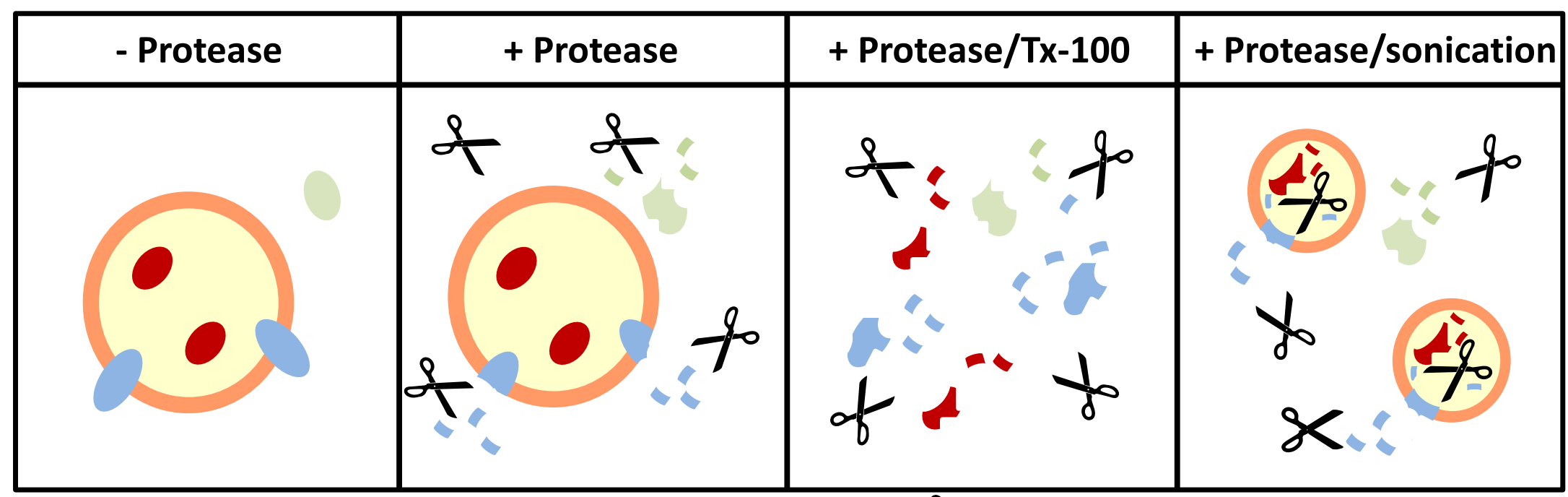

- cytosolic protein, $\bigcirc$ - membrane protein, $O$ - matrix protein, $\&$-protease 